\title{
The Process of Focusing
}

\section{Focus Does Not “Just Happen”}

For many of the sample companies, the focus did not come as a result of an elaborate, expressly stated strategy process. They did not engage consultants to ask them what to do. Nor did they engage in any extensive internal meetings. They also did not pour over extensive customer data. No statistical or Big Data analysis was employed. Yet, it did not simply fall into their lap, either! Focus takes effort.

\section{Finding Focus Is a Journey}

This research will disappoint those readers who believe that focus consists of one decision where companies hit directly upon the right, and final, combination. Rare is the experience of Ricola, where the company embarked almost from the beginning on a focus, which is still being followed today. For most companies, the focus practiced today was settled on after several steps and, at times, only after some painful decisions. The experience of Jura described earlier, in Chap. 8, is a case in point, where the management's focus decision meant eliminating most of the company's previous product line in order to exclusively concentrate on automated espresso machines.

While first developing their business, many company founders followed a narrow path, sometimes tempted to move into different directions once they discovered a potent development or product line. When founders succeed while still moving in their initial direction, they can sometimes get carried away, perhaps even thinking themselves invincible, only to realize later that the risks of losing focus can threaten their entire business. Focus can be likened to pruning a tree or learning how to say no. When some companies face a proverbial crisis of opportunity, returning to selectivity can be difficult. Invariably, this involves selling parts of the business, or company, to narrow the focus on other parts. EAO illustrated this process. 
When the second generation at EAO with Kurt Loosli, Jr., joined the company, the product portfolio included a wide range of products. Older generations of transformers were produced next to a variety of platforms of command and control devices, primarily illuminated push buttons. The company decided to sell off all non-core businesses, including transformers, ${ }^{1}$ and to concentrate exclusively on command and control devices. The company adopted a new vision of completely opening the range of switches to become a leader in HMI products, a business area that had not yet completely evolved. Leadership for EAO did not mean to be the largest in volume but the best in quality, fully addressing all possible interfaces based on the three human senses of feeling, hearing and seeing, while strongly focusing on applications within most demanding environments. ${ }^{2}$

EAO was thus spinning out its older, initial product line to concentrate solely on its new opportunities in HMI interfaces, the source of all of its business today. The company had moved from the initial transformer business to a combination of transformer and HMI devices, to then become solely focused on the latter by dropping the first business.

For its first 30 years, the journey of Komax encompassed its original cable wiring equipment which grew rapidly and was focused on the automotive industry. Forays into other industries, while looking at first promising, did not materialize and the company returned to a more singular focus by divesting its new ventures.

Around 2005, Komax was also looking at other industry applications for growth. Two major sectors were targeted, the medical sector and the photo voltaic (solar) sector. Both offered some of the features that demanded Komax-type wiring machinery, and both were more heavily into assembly automation. While both the medical and the photo voltaic sectors experienced considerable growth early on, exceeding growth in the industrial cable wiring sectors, long-term success proved difficult to secure. The experience during the financial crisis of 2008-2009 might have contributed to the search for alternatives to the wiring business, particularly in the automotive sector. Komax experienced a sales decline of as much as 55 percent from automotive customers during that period, whereas sales in the solar and medical segments remained relatively stable.

In the medical sector, Komax acquired Ismeca, a company active in assembly automation and located in La Chaux-de-Fonds, employing about 120 people, with sales of about CHF 42 mio. Although initial results were promising, the Medtech business never did take off as expected. Similar developments were registered in the solar business. In 2013, Komax reviewed its strategic options leading to the decision to step out of both segments. At that time, wiring systems accounted for 75 percent of sales, the rest going for Medtech ( 20 percent) and Solar. Both segments had a much lower profitability than the core wiring segment. The solar business was sold as part of a management buyout, MBO, in 2014 and the medical business was sold in 2016 to an Italian buyer. ${ }^{3}$

Filtrox underwent a more drastic refocusing. After steady growth and expansion from filters into equipment and processes, the company reached a point where carrying on along both vectors had reached its limits.

\footnotetext{
${ }^{1}$ The spun-out transformer business continues to this day under different ownership.

${ }^{2}$ Adopted from EAO company profile.

${ }^{3}$ Adapted from Komax company profile.
} 
For decades, Filtrox had two large business segments: Filter Media and Machines \& Plants. Machines \& Plants had two further parts. One was media-carrying equipment, which was the smaller part and accounted for about 10 to $20 \%$ of sales. The other part was systems that did not require any filter media. As a result of acquisitions and private investments, Filtrox had grown strongly in the 1990s and at the beginning of the 2000s. Filtrox production covered a broad portfolio, from machines such as wine presses to depth filters for various applications. The company realized that Filtrox was no longer able to cover such a large portfolio and stay innovative. Every product had to be improved constantly, a costly process. In addition, the filter systems for breweries were getting bigger and bigger, and to handle such large individual projects became difficult for a small firm in terms of risk and resources.

If the product portfolio is too broad, we can no longer invest into enough $R \& D$ for all products. Then we'll stay technologically stationary and will be overtaken at some point. If we are to remain innovative, we have to specialize (Rusch, CEO).

Filtrox decided to divest the engineering part of the company. The main reason for selling this business unit was its profitability, which was significantly lower than that of Filter Media. In addition, they wanted to further minimize risk, since they had pursued large individual projects in the Non-Filter Media sector and thus had corresponding longer cycles. The markets had diverged and there were too few synergies between them. Plant construction followed a different logic than the filter media business. One was a classic distributor business, the other a direct business which needed a different approach and other people in sales. Filter Media were considered core business. Everything not related to this core business was sold in 2012. In the process, the company lost almost half of its turnover and, in St.Gallen, employment was reduced from 150 to 90 . After the split, Filtrox became more innovative and grew faster than before, achieving double-digit growth in its core business. All resources could now be directed to one business area, whereas in the past it had to be split between two. In 2020, Filtrox had employed more staff than before the spin-off, but fewer in Switzerland. Of the 350 employees worldwide, 90 were located in St. Gallen. ${ }^{4}$

It's a bit of a special story, a company that develops in this way and then almost cuts itself apart, virtually taking out a large part of the company as a whole so that the rest can develop better. Everybody prefers to get bigger and bigger. But this cut was necessary to generate growth again (Rusch). ${ }^{5}$

\section{Employing Multiple Layers of Focus}

Thus far, the various types of focus have been addressed as if they were singular choices. The typology of focus can be based on industry, business, core competency, technology, and market or a customer franchise, including solution and systems. Most companies researched were employing more than one type of focus, thus layering several focus types together for optimal configuration. Moving from an industry type to a solution type focus greatly affects the breadth of choices offered to customers. No SME can afford to be active in all industries, enter all markets, develop all technologies, in addition to expanding to a customer franchise model at the same time and offering complete solutions for all these pathways. The key is restriction, elimination, and reducing choices to focus on the right focus.

\footnotetext{
${ }^{4}$ Adapted from Filtrox company profile.

${ }^{5}$ Ibid.
} 
As will be covered in later chapters about Segmentation and Product Building Choices, there exist additional types of focus steps that cover the above aspects, implying that some firms layer a multitude of focus strategies to arrive at a competitive approach that is compatible with their resources and skills.

\section{Reaping the Benefit of Focus}

The sections about focusing have highlighted the benefits that stem from concentrating resources on a few core areas, which are defined by industry, technology, customers or wrapped around solutions, and a core customer franchise area. Particularly for SMEs, where resources are always tight, bundling them all in a single area makes the company more competitive.

As many of the documented firms manifest, the focus was almost a given during their early history. Many then succumbed to the notion that this focus might be too narrow and that several legs to the stool might be a form of hedging bets. After a strong start, companies such as Komax, LEM, and Filtrox expanded their market activity. Many of the truly focused firms investigated reached a state of focus only after such an expansion period. The divestments that often followed resulted in a substantial reduction of overall company size and sales, soon to be offset by rapid growth in the chosen core area.

At some companies, $\mathbf{C + M}$, Plumettaz and Rüeger, for example, that process has not yet been completed and the width of their businesses suggests that a further tightening of focus might occur down the road.

In 2018, Plumettaz sales to the Telecom industry amounted to about 50 to 55 percent of total, whereas the other industrial applications together accounted for about 20 percent of sales. The rest came from the railroad segment (oil circulators) and from some remaining agricultural business. Denis Plumettaz, its Executive Director, called this their four-leggedstool strategy. ${ }^{6}$

Cendres + Métaux $(\mathbf{C}+\mathbf{M})$ could look back to a storied history of more than 130 years. Started as a small operation attached to a local pharmacy, the company gradually expanded its operation. Processing and machining precious metal parts gave it an entry into the watch industry and, later on, into the production of dental components used for crowns. Growing steadily over time to reach sales of about CHF 146 mio (2019), the company spread internationally and employed about 350 at its main operations in Biel/Bienne. The company had evolved into a medical component business, accounting now for more than two thirds of sales. $^{7}$

Although a company might adhere to a given focus at one time, changes in the market or industry might require an alteration. This suggests that a chosen focus needs to be consistent with the prevalent megatrends that drive an industry sector. Once they change, a major redirection may become necessary. Plumettaz, one of the

\footnotetext{
${ }^{6}$ Adapted from Plumettaz company profile.

${ }^{7}$ Adapted from Cendres + Métaux company profile.
} 
smaller firms cited above, found its agricultural plow-pulling market for vineyards disappear when the wine industry adopted the practice of letting the grass grow freely in the vineyards. On the other hand, companies such as Jura and Thermoplan benefited from hitching their fortune to the growth of the espresso and latte wave swapping over from Italy and literally circling the world.

\section{Lessons from Focus Journeys}

The loss of focus often comes as a result of opportunity pull, and particularly firms with strong technologies in multiple markets can easily succumb to the crisis of opportunity. For those who have found their way back to focus, or who want to avoid losing it again, there is just one important element to remember: Saying No! Saying no in order to avoid straying from the chosen path of staying focused is both an art, a skill and a resolve that needs to be practiced time and time again.

Focus determines the market space where a company qualifies to play or where the firm intends to play. Observing the 36 researched firms, the rule appears to be: play in one market space only. Those who play in multiple spaces clearly are the exception. When a change of focus becomes imperative, many companies take the difficult step to divest the operations from their earlier focus phase to insure that at any one time, only one market space remains in focus. This is a major difference from larger companies that may operate multiple businesses, competing in multiple market spaces and organizing themselves around several divisions.

Focus alone, as described in this chapter, is not singularly sufficient to narrow the activities of SMEs as documented. Given the chosen market space that is the center of focus, that market space still needs to be subdivided into segments. The researched companies confirm that it is not good practice to take on the entire market space for which a firm qualifies. Instead, further choices restricting activities need to be made.

The process of finding focus around a given activity, or part of the market, tends to make a big company out of a small company. That might sound counterintuitive, but it cuts to the heart of the purpose of focusing. SMEs can, by focusing, overwhelm even larger companies if the SME manages to put more effort, more products, and more variations into a well-described market space than a larger company. The resources of the larger company deployed outside the narrow, focused area of the small company often do not automatically yield a relative competitive advantage for the larger player. This is the point when SMEs can assume the stature of a giant. To find such a niche is one of the core strategic tasks for SMEs.

The discussion of focus in this chapter concentrates on outward-directed focus, as reflected in market activity. There are other areas of focus dealing with inward operations, ranging from purchasing, production, and other value stream activities. Those types of focus will be discussed in the appropriate chapters later on and will offer a chance to delve deeper into the concept of layering when both internal focus and market external focus are combined into a larger bundle. 
The next chapter will discuss segmentation and segment choices. Clearly, there is some overlap between focusing and segmenting, which will be delineated and clarified to demonstrate why it makes sense to treat them separately.

Open Access This chapter is licensed under the terms of the Creative Commons Attribution 4.0 International License (http://creativecommons.org/licenses/by/4.0/), which permits use, sharing, adaptation, distribution and reproduction in any medium or format, as long as you give appropriate credit to the original author(s) and the source, provide a link to the Creative Commons license and indicate if changes were made.

The images or other third party material in this chapter are included in the chapter's Creative Commons license, unless indicated otherwise in a credit line to the material. If material is not included in the chapter's Creative Commons license and your intended use is not permitted by statutory regulation or exceeds the permitted use, you will need to obtain permission directly from the copyright holder.

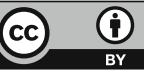

